\title{
ANALYSIS OF CHARACTER VALUES IN THE POETRY OF "LETTER FROM MOTHER" WORKS ASRUL SANI AND "UNKNOWN HEROES" WORKS TOTO SUDARTO BACHTIAR
}

\section{Rokhmaniyah}

Universitas Sebelas Maret

rokhmaniyah@staff.uns.ac.id

\section{Article History}

accepted 30/09/2018

approved12/10/2018

published 30/10/2018

\section{Keywords}

character, poetry, education

\begin{abstract}
This article describes the results of a study based on the importance of character education for the younger generation, especially children. This is due to the fact that the character of the nation is decreasing. For this reason, a research was conducted which aimed to analyze the values of the characters found in the poem "Letter from Mother" by Asrul Sani and "Unknown Heroes" by Toto Sudarto Bachtiar. It is expected that the results of the research can be used by teachers to build the character of their students through classroom learning. This research is literature research with data collection techniques through literature study which contains both poems. Data collection tool using poetry study sheet. The source of this research is poetry and dictionary texts (Large Indonesian Dictionary), as well as experts. To maintain data validity, source triangulation techniques are used. The results showed the character values contained in the poem "Letter from Mother" and "Unknown Hero". Character values are implied in the poetry "Surat dari Ibu" by Asrul Sani and poetry "Unknown Heroes" by Toto Sudarto Bachtiar, namely: independent, nationalist and integrity
\end{abstract}

Social, Humanities, and Education Studies (SHEs): Conference Series https://jurnal.uns.ac.id/shes

p-ISSN 2620-9284 e-ISSN 2620-9292 


\section{PENDAHULUAN}

Pembelajaran berdasarkan Kurikulum 2013 terbaru harus memuat $5 \mathrm{M}$ (Mengamati, Menanya, Mencoba, Menalar, dan Mengomunikasikan), 4C ( creative, critical thinking, comunikative, collaborative), literasi, PPK (Penguatan Pendidikan Karakter), HOTS (berpikir logis, kritis, reflektif, metakognitif, dan kreatif untuk menuju berpikir tinggi tingkat ringgi). Literasi dan PPK dilakukan pada pembiasaan di sekolah. Karakter bangsa merupakan modal dasar untuk membangun bangsa yang kuat dan bermartabat. Istilah "karakter" berasal dari bahasa Yunani, karasso berarti "cetak biru", "format dasar", "sidik" sepert halnya sidik jari". Moenir mengatakan bahwa karakter adalah sekumpulan kondisi yang diberikan begitu saja, given (Kusuma, 2012). Badan Pusat Bahasa mengatakan bahwa karakter diartikan sebagai "bawaan, hati, jiwa, kepribadian, budi pekerti, perilaku, personalitas, sifat, tabiat, teperamen, watak. Berkarakter berarti kepribadian, berperilaku, bersifat, ertabiat dan berwatak (Kemdikbud, 2017)

Generasi muda terutama anak-anak merupakan pemegang tongkat estafet perjalanan kehidupan berbangsa dan bernegara. Jika mereka kurang memahami potensi bangsa dan negara, maka sangat dimungkinkan mereka akan kehilangan jati diri dan karakter yang sebagai bangsa yang bermartabat. Untuk menumbuhkan dan membangun karakter bangsa dapat dilakukan melalui seni. Berbagai seni, baik seni musik, seni tari, seni lukis, seni sastra dapat digunakan sebagai media untuk membangun karakter anak-anak bangsa.

Ajaran budi pekerti dan cinta tanah air banyak tersirat di lagu anak-anak, tarian, lukisan, dan puisi. Khususnya melalui puisi dapat digunakan untuk mengarahkan anak-anak bengsa memiliki sikap: religius, patriotisme, cinta tanah air, rajin belajar, bekerja keras, sopan santun, dsb.

Nilai (value) menurut kamus Poerwodarminto (2008) diartikan harga dalam arti taksiran, harga sesuatu, angka, skor, kadar, mutu, sifat-sifat atau hal penting bagi kemanusiaan. Dalam kehidupan sehari-hari manusia selalu berkaitan dengan nilai.

Dalam Nawa Cita atau sembilan program prioritas Presiden RI periode 20142019, yaitu Nawa Cita yang ke-8 menyebutkan :

"Melakukan revolusi karakter bangsa melalui kebijakan penataan kembali kurikulum pendidikan nasional dengan mengedapnkan aspek pendidikan kewarganegaraan, yang menempatkan secara proporsional aspek pendidikan seperti pengajaran sejarah pembentukan bangsa, nilai-nilai patriotisme dan cinta tanah air, semangat bela negara dan budi pekerti di dalam kurikulum pendidikan Indonesia.

Nawa Cita ini dikenal dengan program Revolusi Karakter Bangsa dan Gerakan Revolusi Mental. Ada lima nilai karakter utama yang perlu dikembangkan sebagai prioritas Gerakan Penguatan Pendidikan Karakter yaitu religius, nasionalis, mandiri, gotong royong dan integritas (Kemdikbud, 2017). Nilai karakter religius merupakan cerminan keimanan terhadap Tuhan yang Maha Esa. Nilai karakter religius meliputi tiga dimensi relasi yaitu hablu minallaah/relasi dengan Tuhan yang Maha Esa, hablu mina annaas/relasi dengan sesama manusia, dan hablu mina alam/relasi dengan lingkungan. Nilai karakter nasionalis merupakan cara berpikir, bersikap, dan berbuat yang menunjukkan kesetian, kepedulian terhadap bangsa, menempatkan kepentingan bangsa dan negara di atas kepentingan pribadi dan kelompoknya. Nilai karakter mandiri merupakan sikap dan perilaku tidak bergantung pada orang lain. Nilai karakter gotong royong adalah perilaku semangat kerja sama, menjalin komunikasi dan persahabatan, memberikan pertolongan kepada orang yang membutuhkan. Nilai karakter integritas adalah nilai yang mendasari perilaku upaya menjadikan diri sebagai pribadi yang dapat dipercaya, memiliki komitmen pada nilai-nilai kemanusiaan dan moral. 
Strategi pelaksanaan pendidikan karakter di sekolah dapat dilakukan melalui empat cara yaitu pembelajaran (teaching), keteladanan (modeling), penguatan (reinforcing), pembiasaan (habituating). Keempat cara ini dilakukan serentak dan berkelanjutan.

Pendidikan karakter dalam pembelajaran digambarkan bahwa ketika sekolah akan menerapkan dan melaksanakan nilai-nilai (karakter) tertentu (prioritas), maka setiap nilai yang akan ditanamkan atau dipraktikkan harus senantiasa disampaikan oleh guru melalui pembelajaran langsung (sebagai mata pelajaran) atau mengintegrasikannya ke dalam setiap mata pelajaran. Bahan pembelajaran/materi pembelajaran yang akan dibelajarkan kepada peserta didik, dikemas dengan memasukkan nilai-nilai karakter. Penanaman karakter lebih jelas dan mengena juga telah dilakukan oleh para penyair sejak zaman angkatan Balai Pustaka (1920) sampai sekarang. Artikel ini mendeskripsikan hasil analisis penanaman karakter melalui puisi angkatan'66, yang berjudul "Surat dari Ibu" karya Asrul Sani dan puisi hasil karya angkatan ' 45 yang berjudul " Pahlawan Tak Dikenak" karya Toto Sudarto Bachtiar.

Puisi merupakan karya sastra yang ditulis secara singkat tetapi padat berisi. Luxemberg (Wardoyo, 2013) mengatakan, "Puisi adalah ciptaan kreatif sebuah karya seni. Ciri khas puisi ditulis berbait-bait, berbeda dengan karya sastra seperti cerpen yang ditulis berparagraf. Hasil karya satra berbentuk puisi terbagi menjadi tiga bagian, yaitu puisi lama, puisi baru, dan puisi kontemporer. Bentuk-bentuk puisi lama, seperti: mantra, pantun, talibun, syair, karmina, dan gurindam. Adapun bentuk puisi baru berdasarkan isinya terdiri dari balada, himne, romansa, ode, epigram, elegi, dan satire. Puisi baru berdasarkan bentuknya terdiri dari: distikon, terzina, kuatrin, kuint, sektet, septima, oktaf, sonata, dan puisi bebas. Puisi kontemporer adalah puisi yang berusaha lari dari ikatan konvensional puisi.

Puisi "Surat dari Ibu" dan "Pahlawan Tak Dikenal termasuk bentuk puisi bebas. Puisi ini tidak terikat dengan jumlah baris dan rima/sajak. Kedua puisi tersebut di atas memiliki nilai-nilai karakter yang sangat padat/tinggi. Puisi tersebut dapat digunakan untuk membangun karakter peserta didik. Untuk itu, puisi tersebut sangat penting dilakukan analisis makna untuk meningkatkan karakter peserta didik.

Kedua puisi di atas sangat bagus jika digunakan sebagai bahan pembelajaran. $\mathrm{Hal}$ ini karena di dalam puisi-puisi tersebut di atas, mengandung nilai-nilai yang dapat digunakan untuk mengembangkan karakter peserta didik. Sebagaimana hasil penelitian Malik dan Santy (2017) yang berjudul "Personal Character Index in The Works Of Raja Ali Haji"yang menyatakan that Raja Ali Haji's works contain nineteen personal character indexes and Raja Ali Haji's works can be referred to as a way of life and is worthy of use as learning materials for character education sourced from the literary works. Artinya, Hasil penelitian menemukan bahwa karya Raja Ali Haji mengandung sembilan belas indeks karakter pribadi dan karya Raja Ali Haji dapat disebut sebagai cara hidup dan layak digunakan sebagai

bahan belajar untuk pendidikan karakter yang bersumber dari karya sastra

Berdasarkan uraian di atas, selanjutnya dirumuskan masalah sebagai berikut: (1) Nilai-nilai karakter apakah yang tersirat dalam puisi "Surat dari lbu" karya Asrul Sani untuk meningkatkan karakter peserta didik?; (2) Nilai-nilai karakter apakah yang tersirat dalam puisi "Pahlawan Tak Dikenal" karya Toto Sudarto Bachtiar untuk meningkatkan karakter peserta didik? Dengan demikian, tujuan penelitian ini, yaitu: (1) untuk menganalisis nilai-nilai karakter yang tersirat dalam puisi "Surat dari Ibu" karya Asrul Sani dan (2) menganalisis nilai-nilai karakter yang tersirat dalam puisi " Pahlawan Tak Dikenal" karya Toto Sudarto Bachtiar. 


\section{METODE}

Penelitian ini menggunakan pendekatan penelitian pustaka. Penelitian pustaka merupakan jenis penelitian kualitatif. Penelitian pustaka pada penelitian ini berusaha mengeksplor nilai-nilai karakter yang terkandung dalam puisi "Surat dari lbu" dan " Pahlawan Tak Dikenal" sehingga dapat digunakan untuk menanamkan karakter peserta didik melalui pembelajaran. Studi pustaka adalah kajian teoritis, referensi, serta literature ilmiah lainnya yang berkaitan dengan budaya, nilai dan norma yang berkembang pada situasi sosial yang diteliti (Sugiono, 2016). Sumber data penelitian ini adalah puisi "Surat dari Ibu" karya Asrul Sani dan puisi "Pahlawan Tak Dikenal" karya Toto Sudarto Bachtiar dan Kamus Besar Bahasa Indonesia (KBBI). Analisis data dilakukan secara kualitatif. Data yang diperoleh berupa kata-kata indah dalam puisi dimaknai berdasarkan KBBI kemudian dilakukan penafsiran terhadap nilai-nilai karakter. Kevalidan data dilakukan melalui teknik triangulasi sumber.

\section{HASIL DAN PEMBAHASAN}

\section{Nilai-nilai Karakter dalam Puisi "Surat dari Ibu" karya Asrul Sani}

Puisi "Surat dari Ibu" termasuk puisi angkatan '45. Puisi ini diciptakan dengan dilatarbelakangi oleh kondisi bangsa yang sedang terjajah, masih bangsa yang bodoh karna dibodohkan oleh penjajah. Puisi yang dilatarbelakangi oleh kehidupan masyarakat yang masih berprinsip "mangan ora mangan asal kumpul" atau "makan atau tidak makan yang penting kumpul" tidak pergi jauh. Oleh karena itu, Asrul Sani berusaha menggugah semangat para pemuda agar tidak mau hidup dikekang penjajah seperti peribahasa "Katak dalam tempurung", tidak pernah melihat dunia luar yang sudah maju dan berkembang. Puisi ini tepat sekali jika diberikan pemahaman kepada peserta didik sebagai generasi muda bangsa Indonesia. Hal ini karena makna puisi ini memiliki nilai-nilai karakter yang sangat tinggi. Sesuai dengan hasil penelitian Iswara (2011) yang berjudul "Pengembangan Karakter Dengan Mengapresiasi Sajak Mohammad Yamin Dalam Pembelajaran Bahasa Indonesia Di Upi Kampus Sumedang" dinyatakan bahwa sejumlah sajak Mohamad Yamin mempunyai nilai yang tinggi terhadap pengembangan karakter. Berikut adalah puisi yang berjudul "Surat dari Ibu".

\section{SURAT DARI IBU}

Pergi ke dunia luas anaku sayang pergi ke hidup bebas!

Selama angin masih angin buritan dan matahari pagi menyinari daun-daunan dalam rimba dan padang hijau.

Pergi ke laut lepas, anakku sayang pergi ke alam bebas!

Selama hari belum petang dan warna senja belum kemerah-merahan menutup pintu waktu lampau.

Jika bayang telah pudar dan elang laut pulang ke sarang angin bertiup ke benua Tiang-tiang akan kering sendiri dan nakhoda sudah tahu pedoman 


\author{
Boleh engkau datang padaku! \\ Kembali pulang, anakku sayang \\ kembali ke balik malam! \\ Jika kapalmu telah rapat ke tepi \\ Kita akan bercerita \\ "Tentang cinta dan hidupmu pagi hari"
}

Karya : Asrul Sani

Ditinjau dari judul puisi menunjukkan bahwa "Surat dari Ibu" terkandung makna pesan/nasihat yang diberikan oleh seorang ibu. Dari judul tersebut mengandung makna pendidikan untuk para pemuda. Bait pertama baris kesatu "Pergi ke dunia luas anaku sayang" mengandung makna seorang ibu yang menyuruh anakknya agar pergi ke mana saja untuk mencari pengetahuan/pengalaman sebagai bekal hidup mandiri. Baris kedua " pergi ke hidup bebas". Artinya, seorang anak muda yang dianjurkan untuk keluar/pergi ke kehidupan yang tidak tergantung pada orang lain. Kehidupan yang mampu menghidupi dirinya. Baris ketiga "Selama angin masih angin buritan" memiliki arti selagi umur masih muda, masih banyak kesempatan. Baris keempat "dan matahari pagi menyinari daun-daunan" mengandung makna ketika kesempatan untuk mendapatkan pekerjaan atau pengalaman masih terbuka. Adapun, baris kelima " dalam rimba dan padang hijau" bermakna di dunia ini, di dalam negeri maupun luar negeri yang berpeluang untuk dicapai. Nilai karakter pada bait pertama ini adalah mandiri.

Bait kedua baris pertama "Pergi ke laut lepas anakku saying" bermakna seorang ibu yang menyuruh anaknya agar keluar/pergi ke kehidupan yang jauh sekalipun. Seorang anak muda tidak hanya mengurung diri di rumah. Baris kedua "pergi ke alam bebas" bermakna untuk pergi ke kehidupan yang bebas menentukan dirinya. Baris ketiga "Selama hari belum petang" bermakna selagi usia belum tua. Baris keempat "dan warna senja belum kemerah-merahan" bermakna tanda-tanda usia tua belum dirasakan. Baris kelima "menutup pintu waktu lampau" bermakna sulit untuk belajar atau mencari pekerjaan karena usia. Nilai karakter pada bait ini adalah mandiri untuk belajar atau bekerja keras sebagai bekal hidup dan mampu menghidupi.

Bait ketiga baris pertama "Jika baying telah pudar" bermakna jika telah terbuka pikirannya.. Baris kedua "dan elang laut pulang ke sarang" bermakna sudah mendapatkan pengetahuan dan pengalaman. Baris ketiga "angina bertiup ke benua" menunjukkan kematangan berpikir. Baris keempat "Tiang-tiang akan kering sendiri" bermakna usia sudah cukup dewasa. Baris kelima "dan nahkoda sudah tahu pedoman" memiliki makna pemikiran sudah matang dan sudah matang memiliki pedoman/cara hidup. Baris keenam "Boleh engkau datang padaku" bermakna diizinkan untuk pulang menemui ibunya. Nilai karakter pada bait ini adalah kerja keras untuk mandiri.

Bait keempat baris pertama "Kembali pulang anakku sayang" memiliki makna seorang ibu yang menyuruh anaknya untuk kembali setelah pergi jauh mencari ilmu atau pengalaman. Baris kedua "kembali ke balik malam" bermakna ibu menyuruhnya pulang berkumpul dengan keluaga. Di waktu malam saatnya keluarga beristirahat dan berkumpul. Baris ketiga "Jika kapalmu telah rapat ke tepi" dapat dimaknai jika apa yang dicita-citakan oleh anak tersebut telah tercapai. Rapat ke tepi dikandung maksud sampai tujuan. Baris keempat "Kita akan bercerita" bermakna anak dan ibu serta keluarga berkumpul mendengarkan cerita pengalaman selama di rantau. Baris kelima " Tentang cinta dan hidupmu di pagi hari" bermakna cerita tentang pengalaman yang menyenangkan bukan cerita yang menyedihkan sehingga menambah semangat untuk 
yang mendengarkannya. Hidupmu di pagi hari, artinya rencana selanjutnya setelah pulang ke kampung halamannya. Tentu akan membangun kampung halamannya agar lebih baik dan maju. Nilai karakter pada bait ini adalah integritas. Artinya, memiliki pesan moral dari seorang ibu agar tetap ingat kepada orang tua, keluarga, atau kampung halamannya untuk berbagi pengalaman.

2. Nilai-nilai Karakter dalam Puisi "Pahlawan Tak Dikenal" karya Toto Sudarto Bachtiar

Puisi yang ditulis tahun 1955, tepat 10 tahun setelah peristiwa 10 November di Surabaya terjadi pertempuran sengit dan memakan banyak korban. Toto Sudarto Bachtiar ialah seorang penyair seangkatan dengan W.S. Rendra yaitu tahun 19501960.

\section{PAHLAWAN TAK DIKENAL}

Sepuluh tahun yang lalu dia terbaring..

Tetapi bukan tidur, sayang...

Sebuah lubang peluru bundar di dadanya..

Senyum bekunya mau berkata, kita sedang perang...

Dia tidak ingat bilamana dia datang..

Kedua lengannya memeluk senapan..

Dia tidak tahu untuk siapa dia datang..

Kemudian dia terbaring, tapi bukan tidur sayang...

Wajah sunyi setengah tengadah

Menangkap sepi pedang senja..

Dunia tambah beku di tengah derap dan suara menderu.

Dia masih sangat muda...

Hari itu 10 November, hujan pun mulai turun..

Orang-orang ingin kembali memandangnya.

Sambil merangkai karangan bunga..

Tapi yang nampak, wajah-wajah sendiri yang tak dikenalnya...

Sepuluh tahun yang lalu dia terbaring..

Tetapi bukan tidur, sayang..

Sebuah peluru bundar di dadanya...

Senyum bekunya mau berkata: "aku sangat muda"

1955

Karya : Toto Sudarto Bachtiar

Judul "Pahlawan Tak Dikenal" menunjuk pada seorang pemuda yang telah mati dan jasadnya tidak dikenal. Bait kesatu baris pertama "Sepuluh tahun yang lalu dia terbaring" artinya 10 tahun lalu terhitung dari tahun 1955, yaitu tahun 1945 terdapat seorang pemuda yang mati terbaring. Baris kedua "Tetapi bukan tidur, sayang" artinya dia terbaring bukan tidur, melainkan sudah meninggal. Baris ketiga "Sebuah lubang peluru bundar di dadanya" artinya di dada pemuda yang terbaring tersebut terdapat luka tembak. Baris keempat "Senyum bekunya mau berkata, kita sedang perang". Artinya, senyum beku menunjukkan seorang pemuda yang sudah meninggal dengan iklas mengorbankan jiwa raga. Nilai karakter pada bait puisi ini adalah integritas. Seorang pemuda yang memiliki jiwa pengorbanan tinggi demi bangsa dan Negara. 
Mempertaruhkan nyawanya demi mempertahankan bangsa dan negara/generasi muda agar bias hidup merdeka. Memiliki nilai2 moral dan kemanusiaan.

Bait kedua baris pertama "Dia tidak ingat bilamana dia dating", bermakna bahwa pemuda tersebut telah lama datang sampai tidak ingat waktu kedatangannya. Baris kedua "Kedua lengannya memeluk senapan", menunjukkan bahwa pemuda tersebut datang ke medan pertempuran mengusir penjajah. Baris ketiga " Dia tidak tahu untuk siapa dia datang, artinya kedatangannya untuk berperang tidak mengerti untuk siapa, melainkan bertempur demi bangsa dan Negara. Baris keempat " Kemudian dia terbaring, tapi bukan tidur saying" menunjukkan bahwa pada akhirnya pemuda tersebut gugur di medan perang, ditegaskan dengan memeluk senapan. Nilai karakter pada bait kedua puisi ini adalah nasionalis, yaitu dia sebagai pemuda yang tidak memikirkan untuk siapa berjuang, tetapi dia hanya berpikir berjuang untuk bangsa dan negara.

Bait ketiga baris pertama" Wajah sunyi setengah tengadah". Artinya, pemuda tersebut sudah tidak peunya harapan hidup lagi karena tertembak. Baris kedua "Menangkap sepi padang senja", bermakna pemuda itu telah senja/tidak punya harapan. Baris ketiga "Dunia tambah beku di tengah derap dan suara menderu". Baris keempat "Dia masih sangat muda". Artinya, dunia tidak segera membantunya, hanya ramai berkomentar bahwa mereka yang gugur masih sangat muda. Nilai karakter pada bait ini adalah integritas dan nasionalis.

Bait keempat baris pertama "Hari itu 10 November, hujan pun mulai turun" menunjukkan bahwa peristiwa gugurnya pemuda untuk mempertahankan kemerdekaan adalah tanggal 10 November yang sekarang kita kenal hari Pahlawan. Orang-orang sedih hujan tangis. Baris kedua, "Orang-orang ingin kembali memandangnya", artinya masyarakat ingin kembali melihat pemuda yang gugur di medan pertempuran untuk menunjukkan berduka/belasungkawa. Bait ketiga "Sambil merangkai karangan bunga". Artinya, menunjukkan berduka sekedar merangkai karangan bunga. Baris keempat "Tapi yang nampak, wajah-wajah sendiri yang tak dikenalnya". Artinya, para pemuda yang gugur tidak bisa dikenalnya.

Bait kelima baris pertama "Sepuluh tahun yang lalu dia terbaring", artinya di tahun 1945, 10 tahun dihitung dari tahun 1955 dimana tahun ditulisnya puisi ini seorang pemuda gugur di medan tempur. Baris kedua "Tetapi bukan tidur, sayang...." artinya pemuda yang terbaring adalah meninggal. Baris ketiga "Sebuah lubang peluru bundar di dadanya" Pemuda yang terbaring karena mati tertembak dadanya. Baris keempat "Senyum bekunya mau berkata "aku sangat muda"', menunjukkan bahwa pemuda yang gugur tertembak masih sangat muda, tetapi rela mengorbankan dirinya untuk kepentingan bangsa dan Negara. Nilai karakter bait ini adalah nasionalisme dan integritas.

\section{SIMPULAN}

Berdasarkan uraian di atas maka dapat disimpulkan sebagai berikut.

1. Nilai-nilai karakter yang tersirat dalam puisi "Surat dari Ibu" karya Asrul Sani, yaitu: mandiri dan integritas.

2. Nilai-nilai karakter yang tersirat dalam puisi "Pahlawan Tak Dikenal" karya Toto Sudarto Bachtiar, yaitu: nasionalis dan integritas.

\section{DAFTAR PUSTAKA}

Kementerian Pendidikan dan Kebudayaan Republik Indonesia (2017) Konsep dan Pedoman Penguatan Pendidikan Karakter Tingkat Sekolah dasar dan Sekolah Menengah Pertama, Jakarta : Kemdikbud

Kusuma, D. (2012) Pendidikan Karakter Kajian Teori dan Praktik di Sekolah. Bandung: Remaja Rosdakarya

Malik, A., \& Shanty, I. L. (2017). Personal Character Index in The Works Of Raja Ali Haji. Int J Inf Technol Bus Manag, 58(1), 22-34. 
SHEs: Conference Series 1 (2) (2018) 1-8

Poerwadarminta. W.J.S. (2008). Kamus Umum Bahasa Indonesia. Jakarta : Balai Pustaka

Sugiyono. (2016). Metode Penelitian (Pendidikan pendekatan kuantitatif, kualitatif dan $R \& D)$. Bandung: Alfabeta.

Wardoyo, M. Sigit. (2013). Teknik Menulis Puisi. Yogyakarta: Graha IImu.

Iswara, P. (2011). Pengembangan Karakter dengan Mengapresiasi Sajak Mohammad Yamin dalam Pembelajaran Bahasa Indonesia di UPI Kampus Sumedang. Quo Vadis Seni Tradisi. Bandung: UPI 